\title{
Implementation of Information and Communication Technologies in the Process of Future Psychologists' Training in Consideration of Their Learning Motivation
}

\author{
Ponomarenko Tetiana and Zelenin Vsevolod
}

\begin{abstract}
This article covers the topicality of the implementation of information and communication technologies in the process of future psychologists' professional training. We have studied students' attitude toward the implementation of educational new forms and established the type of students' learning motivation. The results of the empirical research have indicated that students consider it appropriate to implement online forms of learning in the educational process. We have found out that part-time students receiving the second education are more focused on mastering professional knowledge and skills, and there are students who are focused only on obtaining the higher education diploma among full-time students. We have identified five groups of obstacles that arise during the implementation of online learning forms in the educational process of students-psychologists and three groups of development resources that are necessary for the effective implementation of the educational process in the online format. Thus, we see the prospects for further research in the study of the level of digital competence development among the University teachers of psychological courses in higher education and their attitude toward the implementation of information and communication technologies in the educational process of future psychologists.
\end{abstract}

Index Terms-Students' learning motivation, information and communication technologies (ICTs), information and communication competence, media competence of future psychologists.

\section{INTRODUCTION}

Ukraine, as the whole world, is currently experiencing significant changes in all spheres of the society. These changes are due to information and communication technologys development and the global pandemic COVID-19. We are increasingly observing the systematic implementation of information and communication technologies (ICTs) in our lives. This is caused by a number of positive and negative factors. Technology development, scaling of projects, cooperation between different countries, and European integration has become a positive impetus for the implementation of ICT in the professional and everyday life of the society. However, negative factors were the first signal for many Ukrainian experts to move to the online space in their professional activities. Almost all countries of

Manuscript received July 25, 2021; revised September 19, 2021. This study is supported by National Pedagogical Dragomanov University, Ukraine.

The authors are with the Department of Political Psychology and International Relations, Faculty of Psychology, National Pedagogical Dragomanov University, 01601, Kyiv, Pyrogova str., 9, Ukraine (e-mail: 19fmad.t.ponomarenko@std.npu.edu.ua,v.v.zelenin@npu.edu.ua). the world faced a forced transition to a remote format of work due to the global pandemic (COVID-19) in the spring 2020. Educational institutions switched to distance learning, and the vast majority of them were not ready for it, as learning in this way requires proper hardware, software, and a high leve of information and communication competence of University teachers and students.

The market for psychological and educational services is also gradually moving to the online format. Practical psychologists not only conduct individual consultations with the help of services and applications for video conferencing (Zoom, Google Hangouts Meet, Skype, Bigbluebutton, YouTube Live, Microsoft Teams, Skype, and messengers), but they also organize webinars, master classes, trainings, online marathons, psychological online quests and online conferences, live broadcasts on Facebook or Instagram, stories, informational and motivational videos for their YouTube and Telegram channels, and comedy videos for the youth network TikTok. Educational institutions or University teachers in person create their own distance courses; record video lectures; and conduct online trainings, seminars, and conferences. In this way, professional activity allows one to be more flexible; "move with the time"; work with clients anywhere in the world; stay in touch; travel, move to another city or country if necessary; and find work during epidemics and pandemics. This global trend has already shown its positive results and continues to develop systematically.

At the present time, one of the urgent needs of the educational system is to train highly qualified and competitive professionals who will be ready to work in a constantly changing environment. Therefore, there is a need for professionals to expand the diversity of the educational process, intensify the cognitive activity of students, involve modern learning formats, form the professional motives and practical experience, expand their interests, and create clear ideas about further professional activities taking into account the latest trends. Thus, it is important to study the prospects for the development of information and communication competence of psychology students in accordance with current trends in the market of educational and psychological services and the type of learning motivation of future professionals.

\section{LITERATURE REVIEW}

Innovations in various spheres of human life have led to the development of digital literacy, media competence, and active implementation of ICT in the training of future 
professionals. Studies examining the availability, opportunities, and difficulties of using ICT in higher education have gained popularity [1]; features and ways of development of digital competence, digital literacy, and digital culture of students [2], [3]; and scientists have considered the main platforms and tools for modernization and digitization of higher education [4].

Scientific researchers are interested in how ICTs affect the training of students. Studies demonstrate that ICTs have a positive effect on improving students' self-efficacy and interest in the learning process [5]. They contribute to the academic growth and improvement of digital knowledge and skills, which will greatly help them in their future professional activities. Currently, the policy of developing possible schemes for implementation of innovative technologies in education at the state level is gaining strength [6].

The integration of ICT in the educational process requires a high level of IC competence of all the participants. Thus, $\mathrm{O}$. Spirin defined IC competence as the proven ability of one to use in practice ICTs to meet one's own individual needs and solve socially significant, including professional, problems in a particular subject area [7]. In turn, N. Morze and A. Kocharian defined IC competence as the ability of an individual to use in practice ICTs autonomously and responsibly to meet individual needs and solve professional problems in a particular subject area or activity [8]. Additionally, V. Logvinenko believed that the IC competence of the specialist is a set of competences in the professional and computer-information fields of knowledge that determine the readiness of a future specialist to carry out professional activities and have the ability to perform necessary actions in the informatization of the society [9].

Media education and media literacy of University teachers and students are developing along with the implementation of ICT in the training process [10]-[12]. Social media have a special place in education. University teachers observe the positive impact of social networks on the educational process of students, but they note their reluctance to maintain public accounts due to excessive intrusion into personal space. They state that communication with colleagues through social media is constructive and appropriate but is not such with students [13].

The works of scientists involved in the creation of media texts (for publications on social networks, websites, and blogs), and determination of the relationship between the components of media texts content, structure, features of presentation and language design are crucial for the training of psychology students [14].

However, all these achievements will be in vain without the interest of the students in receiving high-quality educational services, focus on further professional activities, and the variability of today's world. Obviously, along with the study of innovations in education, we come along research related to students' learning motivation. Thus, T. Ilyina singled out three types of students' learning motivation (orientation on knowledge, on mastering professional skills, and on obtaining the diploma of higher education) and developed the method of their diagnosis [15]. In her thesis, N. Pavlova observed that the content of students' motivation at pedagogical Universities varies depending on the training phase. Professional-pragmatic motivation and cognitive-professional motivation appear only among the students in the third and fourth years of study [16].

Current research indicates that motivation has an impact on not only students' academic performance [17], but also their subsequent professional achievements [18].

At the same time, we have observed that motivation of students is also connected with their competence in the field of communication, which is especially relevant for future psychologists, whose leading tool is communication with clients. In turn, effective communication in the process of large-scale digitalization of psychological services is an important factor in the effectiveness of such activities and the competitiveness of the specialist [19]. By contrast, studies made by Romanian scholars [20] have demonstrated that communication skills of the subjects of the educational process have a great influence on the academic success of students. Owing to the high level of their communicative competence, University teachers provoke interest and motivate students for new achievements.

Therefore, we see that the problem of ICT implementation in the educational process and the study of the students' motivation are relevant at present. However, there is a lack of works related to the study of the role of motivation in the use of innovative technologies in the training of future psychologists. This situation has led to the topicality of our research.

The aim of this article is to investigate the attitude of psychology students toward the implementation of ICTs in the process of their professional training in consideration of the type of students' learning motivation.

\section{PeCuliarities of ICT ImPlementation IN THE PROCESS OF FUTURE PSYCHOLOGISTS' TRAINING}

The main task of higher education institutions is to train specialists for life in the new conditions of the information society. In turn, this causes the issue of curriculum transformation; search for new forms, reformed methods, technologies and tools for teaching or even new courses; development of information and communication competence of all subjects of the educational process; and implementation of ICT in not only the formal but also the non-formal and informal education.

These changes should be based on two main skills, according to D. Halpern and his colleagues [21]: 1) the ability to navigate the ever-increasing flow of information quickly and separate the necessary information and 2) the ability to perceive and apply the information obtained. Meanwhile, such innovations require a high level of digital competence and motivation of future psychologists to acquire professional knowledge and skills.

The use of ICT in educational and professional activities requires the students of psychology to have technical (digital) knowledge and skills. Consequently, the digital competence of the individual as a set of personal, technical and intellectual (digital) skills is necessary for life in the modern world [2], [3]. 
However, Tracy M. Scull and his colleagues [22] emphasize taking into account the motivational stage in the development of students' digital competence and the implementation of ICTs in the educational process to explain all the benefits students will receive, for better, more interesting training and further competitive professional activity. Therefore, it is necessary to not only implement ICT in the process of future psychologists training but also develop students' competence in this way, with the prospect of implementing new work forms in their professional activities. Meanwhile, recent studies [5], [17], [18] demonstrate that the implementation of ICT in the training of future professionals develops their learning motivation and encourages the mastery of new professional competences and search for interesting forms of professional fulfillment.

There are many approaches to understanding the phenomenon "motivation" in the psychological literature, but they all can be divided into two areas: motivation as 1) a dynamic formation, as a process and mechanism, and 2) a set of certain factors that determine human behavior. Our study was conducted in the second direction [15]. We are inclined to believe that the motivation of students to study has three factors: focusing on knowledge - it indicates a high cognitive interest; focusing on mastering professional skills-it demonstrates focus on mastering the profession and interest in current trends in science and practice; focusing on diploma - it shows the desire to obtain a diploma in the formal acquisition of knowledge, the desire to find alternative ways when passing exams and tests [15].

Thus, there is a need to study the attitude of psychology students toward the implementation of ICTs in the process of their training and establish the type of their learning motivation.

\section{Methodology, Results, AND Discussions}

\section{A. Methodology}

The empirical study was conducted in the period from December 2020 to March 2021. We used the following methods: conversation, observation, testing, surveys, and methods of mathematical data processing (Pearson's correlation coefficient). The study involved two samples of respondents. The first sample consisted of full-time students of third and fourth study years, in the Faculty of Psychology, National Pedagogical Drahomanov University (Ukraine, Kyiv), aged from 19 to 22 years $(\mathrm{n}=88)$. The second sample consisted of part-time students of second and third study years, second higher education, bachelor's degree, Faculty of Psychology at the National Pedagogical Drahomanov University, aged 22 to 37 years $(n=36)$. All participants of the research were offered "Methods of learning motivation study at the University" by T. Ilyina [15], which includes three scales: The "Acquisition of knowledge" scale shows the desire to obtain important professional knowledge and demonstrates the curiosity of students; the "Mastering the profession" scale demonstrates the desire of students to acquire the professional knowledge they need and form professionally important personal qualities, skills, and abilities; and the "Obtaining a diploma" scale shows the desire to obtain a diploma during the formal acquisition of knowledge.

Also, we created for students the questionnaire "Study of the attitude of the student-psychologists toward the implementation of ICTs in the process of their professional training". The questionnaire consisted of 10 questions. Questions No. 1-6 are formulated by the Likert scale. Questions No. 7-10 are open-type questions where student-psychologists are offered to express their own opinions.

1) Do you have technical skills to study online (register for a course or a webinar, go to the webinar room, find the necessary information on the internet, repost the publication, or download the necessary file or video? Assess the level of your media competence (where $1=\mathrm{I}$ can do almost nothing, and $10=\mathrm{I}$ can perform all the above-mentioned actions easily)?

2) Do you practice learning online? Evaluate the intensity of its use (where $1=\mathrm{I}$ have attended some of the online learning events several times, and $10=$ I regularly attend online events (courses, trainings, workshops, webinars, conferences, etc.).

3) Do your university teachers teach online? What online forms do they implement? Evaluate the intensity of its use (where 1 = They sometimes send recorded versions of lectures or workshops, and $10=$ They regularly teach online and create additional online courses and information chats for each learning course).

4) Do you consider it expedient to implement modern online forms (webinar, online marathon, online master classes, etc.) in the process of psychology students' training? Express your opinion (where $1=\mathrm{I}$ am not against the implementation of ICTs in the educational process, and $10=$ I consider it necessary to implement modern ICTs in the learning process and understand the opportunities and prospects they open up for me).

5) Are you familiar with such modern forms of professional activity of a psychologist as a psychological online quest, online intensive or online marathon? Express your opinion (where $1=$ Yes, I know these phrases, and $10=\mathrm{I}$ have experience in such formats).

6) Do you consider it appropriate to teach certain courses or separate subjects in the format of a psychological quest, online intensive course, or online marathon? Evaluate the level of expediency (where $1=\mathrm{I}$ can try, and $10=\mathrm{I}$ fully support this idea and understand its effectiveness for my professional training).

7) What obstacles may arise during the implementation of online format in the training of future psychologists?

8) What resources are necessary to bring in modern online forms of education for students of psychology?

9) What study courses would be the most appropriate for the usage of modern online teaching forms?

10) What study courses is online teaching categorically unacceptable for?

Our individually designed questionnaire allowed evaluation of the level of IC competence mastery by student-psychologists at three levels (low, average, and high). The low level of IC competence mastery (1-3 points) was assigned to those students who do not have IC competence 
even at the level of an everyday user. The average level of IC competence mastery was assigned to those future professionals who are confident internet users and who try to use their knowledge and skills in the learning process. We have assigned the high level of IC competence mastery for those respondents who are confident in ICT and who actively use their opportunities in the process of obtaining professional education and understand the prospects of this activity in such a way.

The following results have been obtained through respondents' psychodiagnostic testing, individually designed questionnaire, interviews with students during the questionnaire, and episodic, including non-standardized, field observation of them during training (as a part of teaching practice).

\section{B. Type of Learning Motivation of Future Psychologists}

In the framework of theoretical and empirical research, we found out that the high level of motivation and interest of students in the future profession is one of the resources for the development of digital competence of an individual. We suggested that the interest in studying and students' attitude toward the implementation of innovative forms and methods in the educational process depends on the type of learning motivation. Therefore, we diagnosed the type of students' motivation (Fig. 1) with the help of "Methods of learning motivation study at the University" by T. Ilyina.

Full-time students having the low level of motivation to acquire new knowledge are typically focused on obtaining a diploma of higher education, or they seek to postpone service in the army (this applies to males). They are not interested in learning; they do not do homework; and they do not learn on their own. Future psychologists focused on acquiring knowledge at the average level try to do all homework's, listen carefully to the lecturer, read additional professional literature, and sometimes attend additional professional online and offline events. In addition, student-psychologists who have demonstrated the high level of motivation to master new professional knowledge very conscientiously perform all tasks are present at all classes and listen carefully to the University teacher. They are very active during the lectures and seminars; they ask many questions and read additional professional literature. They practice informal and non-formal education actively: They attend career development courses (psychoanalysis, psychodrama, symbol drama, cognitive-behavioral therapy, Gestalt therapy, logotherapy, etc.) and participate in online and offline conferences.

Future professionals focused on mastering professional skills at the average level are active during seminars and practical classes; they read additional literature and sometimes attend professional events. Students showing the high level of motivation to master professional skills are very responsible while doing the tasks, are active during the seminars and practical classes, and attend additional classes of University teachers (optional classes and task forces). They participate and conduct their own master classes and trainings, organize online marathons, and start practicing their professional activities during their study at the University.
Psychology students focused on obtaining the diploma at the low level are more determined to get professional knowledge and skills. At the average level, they are more often determined to have a profession, but they are also interested in the formal side of the matter.

Part-time students in second and third years of study receiving the second higher education showed us the following results (Fig. 2).

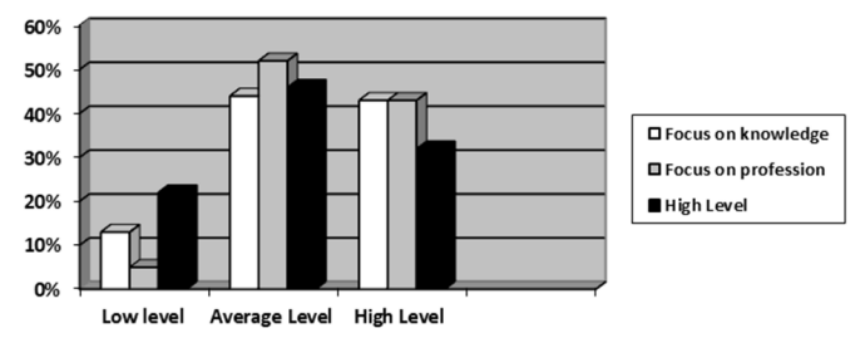

Fig. 1. The correlation of indicators among full-time students in consideration of their learning motivation (in \%).

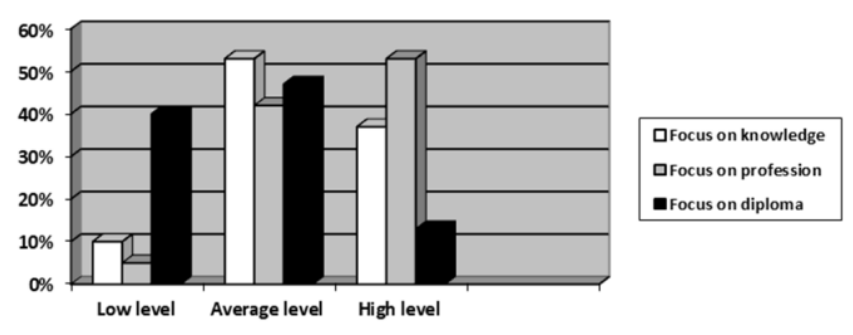

Fig. 2. The correlation of indicators among part-time students in consideration of their learning motivation (second higher education, in \%)

Students having the low level of motivation to acquire new knowledge are typically not interested in learning, but they pursue personal goals by obtaining a second higher education (several diplomas as a good status or the need to have documentary evidence of their knowledge and skills). Future professionals demonstrating the high level of focus on acquisition of new knowledge and professional skills are typically honest in the attitude toward learning and interested in the latest trends in science and practice.

Students focusing on obtaining a diploma at the low and average levels are more aimed at gaining professional knowledge and skills. For students getting the second education, orientation on a diploma at the high level may be related to the need for a document certifying a person's qualification level.

However, we used the Fisher's angular transformation criterion $(\varphi *$ Fisher's criterion), which is designed to compare two samples on the frequency of the data of the studied effect. It assesses the significance of differences between percentages of two samples (full-time and part-time students), which registered an interesting effect, namely the dominant type of orientation (focus on obtaining the document of higher education rather than professional knowledge and skills).

We calculated that $\varphi^{*}=2.623$. Thus, we see that part-time students receiving the second education are more focused on mastering professional knowledge and skills, and among full-time students there are those who are focused only on obtaining a University diploma. Thus, we can conclude that such students will not be interested in implementation of ICTs in the training of future psychologists because they 
have a low cognitive interest in the future profession and are focused on obtaining a higher education diploma.

\section{Analysis of the Attitude of Student-Psychologists toward the Implementation of ICTs}

Later, we investigated the level of digital competence of students and found that a vast majority of students (90\%) have the necessary technical skills to study online (Fig. 3).
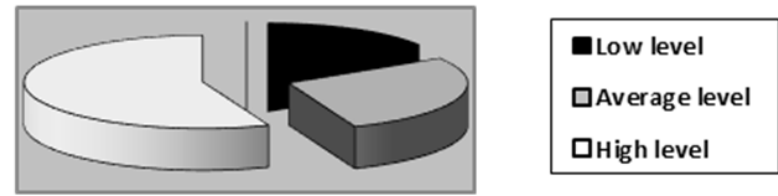

Fig. 3. Indicators of the development level of IC competence among student-psychologists (in \%).

The high level (56\%): Students know how to use social networks and have a good mastery of messenger functionality; they know how to work with a webinar room, online learning platforms, and cloud storage.

The average level (8\%): Students use social networks and messengers, but they are not familiar with all their features; they know how to work in webinars and use cloud storage but often have problems with online learning platforms.

The low level (16\%): Students often have questions about the functionality of social networks and messengers and webinar rooms; they are typically not even familiar with learning platforms and cloud storage. These results indicate the formation of basic technical knowledge and skills for learning in modern online formats.

Also, we investigated the possible correlations between the types of learning motivation among psychology students and their level of information and communication competence using Pearson's correlation coefficient.

The results indicated that there is a direct relationship (rxy $=0.751715$ and $\mathrm{rxy}=0.698084$ ) between the level of IC competence of student-psychologists and the focus on obtaining professional knowledge and mastering professional skills. This means that the higher the level of IC competence of a future psychologist, the higher the level of his/her focus on mastering knowledge and professional skills.

In turn, we investigated the inverse relationship ( $\mathrm{rxy}=$ $-0.69604)$, which states that the lower the level of IC competence of students, the higher the level of their orientation to obtain a higher education diploma. Thus, we can conclude that students focused on acquiring professional knowledge and skills are more interested in implementation of ICT in the educational process than students who only want to obtain a higher education diploma. First, we assume that this is due to the fact that such students clearly understand that the quality of education will change significantly for the better, and they are aware of the prospects that ICTs open up for them in the professional environment. Second, it allows teachers diversify the training material, which in turn increases the interest in the future profession.

However, all students consider it appropriate to implement modern online forms in the educational process. They associate it with the constant development of information technologies; the demands of the modern market of psychological services; convenience and time savings; and the ability to meet global trends and be competitive, be active in science, be mobile, develop professional skills, work with prominent practitioners from around the world, and study in several Universities or on two specialties at the same time.

Training in this way is especially effective during periods of abnormal weather, poor functioning of heating systems in educational buildings and dormitories and in a global pandemic (COVID-19), or seasonal epidemics of influenza and other diseases. Such innovations are especially relevant for part-time students, because studying in this way gives them the opportunity to get an education without attending University (in their place of residence or work), which in turn significantly saves money on rent for the study session, travel, vacation without pay, etc.

At the same time, we investigated whether University teachers of psychological courses use modern ICT in the training of future psychologists. Thus, according to students' comments, $60 \%$ of teachers use ICT - they conduct webinars, workshops, offer students' video courses, video lectures; recommend watching movies that illustrate aspects of the topic being studied; prepare learning subjects on the platforms Moodle and Prometeus; record lectures and teach on YouTube. However, this activity takes place at different levels (Fig. 4).

From the diagram, in the figure, we see that only $15 \%$ of University teachers use many innovative forms of learning; $25 \%$ of University teachers conduct webinars, workshops and share links to resources that cover a topic or a course; and $60 \%$ of University teachers only share the work results of their colleagues. According to the students, modern forms of online learning can be implemented at all courses. For theoretical courses, it is advisable for one to use video lectures, webinars, and chats in messengers. Practical courses require online conferences, psychological quests and marathons, workshops and trainings, online intensives, sometimes entire video courses, and information chats. However, it is important to have a certain percentage (approximately 30\%) of classroom classes as well.
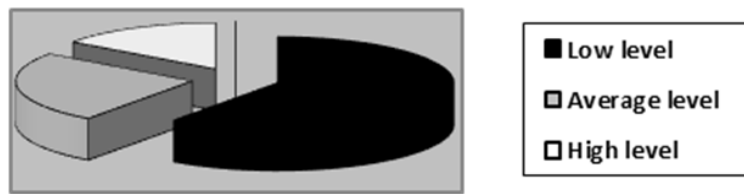

Fig. 4. Indicators of University teachers' use of ICTs in the training of future psychologists (in \%).

After that, we assessed the awareness of student-psychologists in modern forms of implementation of the psychologist's professional activities in the online space. Sixty-five percent of student-psychologists are familiar with such modern online forms of work as psychological online quest, online intensive, and online marathon. They consider it appropriate to teach certain topics or courses in this format. However, only $10 \%$ of University teachers use online marathons in the process of teaching students, but they do not conduct quests and intensives.

These results indicate a sufficient level of awareness of students in the latest trends in the market of psychological 
services. We identified five groups of the obstacles that can prevent all subjects of the educational process to work online after analyzing students' judgments:

1) lack of proper technical support (educational institutions, dormitories, and University teachers and students);

2) low motivation of university teachers to master modern trends and new forms of professional activity;

3) low cognitive activity of students;

4) low level of digital competence and communicative media competence of university teachers; and

5) low level of digital literacy of student-psychologists.

From the results of the students' survey, we have identified three groups of the development resources that will help to improve the training of future professionals with the implementation of ICT:

1) proper technical equipment (University and dormitories);

2) good work of the management of the institution; and

3) interest of teachers and students.

Our analysis also demonstrated that $92 \%$ of students are additionally engaged in self-education, which, in turn, demonstrates students' interest in learning, and they focus on further professional practice (Table I).

Summing up our research, we can state that students consider it appropriate to implement modern online forms of learning (ICTs) in the training of future psychologists. However, only $56 \%$ of students have the high level of development of technical (digital) knowledge and skills to learn in this way. Additionally, only $30 \%$ of university teachers practice teaching online at the average and high levels. Ninety-two percent of students of psychology practice information education, and 50\% of students additionally study online. Thus, we can conclude that the implementation of ICTs in the training of psychology students will help them to develop digital competence, increase their learning motivation and interest in future profession.

TABLE I: SELF-EDUCATION OF STUDENT-PSYCHOLOGISTS

\begin{tabular}{|l|c|}
\hline Type of activity & Quantity in \% \\
\hline Learning online & $50 \%$ \\
\hline Reading additional professional literature & $90 \%$ \\
\hline Attending additional lectures & $83 \%$ \\
\hline Attending additional workshops & $49 \%$ \\
\hline Attending trainings and workshops & $76 \%$ \\
\hline Attending psychology and personal growth festivals & $54 \%$ \\
\hline Participation in conferences & $29 \%$ \\
\hline Participation in online events & $43 \%$ \\
\hline $\begin{array}{l}\text { Study at courses on a certain psychological approach } \\
\text { psychoanalysis, psychodrama, symbol drama, Gestalt } \\
\text { therapy, cognitive-behavioral therapy, logotherapy, } \\
\text { etc.) }\end{array}$ & $9 \%$ \\
\hline Attending webinars and workshops online & $41 \%$ \\
\hline Participation in highly specialized online conferences & $27 \%$ \\
\hline
\end{tabular}

\section{CONCLUSION}

The results of the theoretical review indicated that the current stage of the development of education requires the implementation of ICTs in the educational process of future psychologists. Such innovations develop students' digital literacy and increase their learning motivation as well. Today, the most effective and well-known forms of ICT implementation in education and psychological practice are webinars, online workshops and trainings, psychological quests, intensive and online marathons, video lectures, video courses, online conferences, etc. Learning in this way allows you to provide theoretical material, develop professional skills, and increase students' interest and learning motivation.

The results of the empirical study indicated that part-time students receiving the second education are more focused on mastering professional competences, and a third of full-time students are focused only on obtaining a higher education diploma. Thus, we can conclude that such students will be less interested in implementation of ICT in the training of future psychologists because of a low cognitive interest in the future profession, as they are focused on obtaining a document as evidence of higher education.

According to the results of the study, we found that students consider it appropriate to implement modern online forms of education in the training of future psychologists. Fifty-six percent of students have the high level of development of the necessary technical skills to study online. Ninety-two percent of student-psychologists practice self-education, and $50 \%$ of students study online additionally. Thus, the obtained results indicate a sufficient level of digital competence formation of students to study in the new format, the high level of awareness in modern world trends in the market of educational and psychological services, and a positive attitude toward the implementation of ICTs in the process of their training. However, using Pearson's correlation coefficient, we found that students of psychology focused on acquiring knowledge and professional skills are more interested in implementation of ICTs in the educational process than students who only want to obtain a higher education diploma.

We have also identified five groups of obstacles that arise during the implementation of ICT in the training of psychology students:

1) lack of proper technical equipment,

2) low motivation of university teachers,

3) low cognitive activity of students,

4) low level of media literacy and communicative media competence among university teachers, and

5) low level of media competence among students.

We distinguish three groups of development resources that are necessary for the effective implementation of the educational process in the online format:

1) proper technical equipment,

2) good work of the management of the institution, and

3) high level of motivation and leadership skills of University teachers (assertiveness, active life position, self-confidence, sociability, tolerance to new experiences, willingness to take risks, high adaptability, etc.).

Thus, the implementation of ICTs in the training of future psychologists will help them to develop information and communication competence and master the latest trends in psychological science and practice. It will also increase their motivation and interest in future professions and help to find interesting areas for professional fulfillment.

The limitation of our study is the lack of information about the level of IC competence development among University teachers of psychological courses and their attitude toward the implementation of ICT in the educational process of psychology students. After all, University teachers are active 
subjects of the educational process; they can both promote and resist the implementation of the latest learning technologies. We see prospects for further research in the study of the development level of digital competence among university teachers of psychological courses in higher education and their attitude toward the implementation of ICTs in the educational process of future psychologists.

\section{CONFLICT OF INTEREST}

The authors declare no conflict of interest.

\section{AUTHOR CONTRIBUTIONS}

Ponomarenko Tetiana conducted the research and wrote the paper; Zelenin Vsevolod analyzed the data; and all authors have approved the final version.

\section{REFERENCES}

[1] M. Hammond, "What is an affordance and can it help us understand the use of ICT in education?" Education and Information Technologies, vol. 15 , pp. $205-217,2010$.

[2] L. Gavrilova and J. Topolnyk, "Digital culture, digital literacy, digital competence as modern educational phenomena," Information Technologies and Teaching Aids, vol. 5, pp. 1-14, 2017.

[3] S. Pöntinen and S. Räty-Záborszky, "Pedag.ogical aspects to support students' evolving digital competence at school," European Early Childhood Education Research Journal, vol. 28 (2 SI), pp. 182-196, 2020.

[4] D. Dzvinchuk, O. Radchenko, O. Kachmar, I. Myskiv, and N. Dolinska, "Analysis of platforms and tools of open study in the conditions of postmodern education," vol. 12, pp. 125-144, 2020.

[5] H. Shenghua, J. Yichao, Y. Hongbiao, and S. Morris, "Does ICT use matter? The relationships between students' ICT use, motivation, and science achievement in East Asia," Learning and Individual Differences, vol. 86, article no. 101957, 2021.

[6] S. Ansuman and N. Satya, "A study on policies and implementation of information and communication technology (ICT) in educational systems," Materials Today: Proceedings, 2020.

[7] O. Spirin, 'Information-communication and information competences as components of the system of professionally-specialized competences of a computer science teacher," Information Technologies and Teaching Aids, vol. 5, pp. 1-16, 2005

[8] N. Morze and A. Kocharian, "Model of the standard of ICT competence of university teachers in the context of improving the quality of education," Information Technology and Teaching Aids, vol. 43, pp. 27-39, 2014.

[9] V. Logvinenko, "ICT competence and ICT competence of the future specialist," Theory and Methods of Teaching Mathematics, Physics, Computer Science, vol. 7, pp. 121-130, 2013.

[10] L. Romero and M. Gómez, "Teaching media literacy in colleges of education and communication," Comunicar, vol. 22, pp. 187-195, 2015.

[11] O. Semenog, O. Semenikhina, P. Oleshko, R. Prima, O.Varava, and R. Pykaliuk, "Formation of Media Educational Skills of a Future Teacher in the Professional Training," Revista Românească pentru Educaţie Multidimensională, vol. 12, pp. 219-245, 2020.

[12] G. Alcolea-Díaz, R. Reig, and R. Mancinas-Chávez, "UNESCO’s Media and Information Literacy curriculum for teachers from the perspective of Structural Considerations of Information," Comunicar, vol. 28, pp. 103-114, 2020.
[13] M. Hasiloglu, H. Calhan, and M. Ustaoglu, "Determining the views of the secondary school science teachers about the use of social media in education," Journal of Science Education and Technology, vol. 29, pp. 346-354, 2020.

[14] P. Jones, A. Turney, H. Georgiou, and W. Nielsen, "Assessing multimodal literacies in science: semiotic and practical insights from pre-service teacher education," Language and Education, vol. 34, pp. 153-172, 2020.

[15] T. Ilyina, Methods for Studying the Motivation of Learning at a University, M.: Vlados-press, 2013.

[16] N Pavlova, "Motivation of educational activities of students of a pedagogical university," Extended abstract of Candidate's thesis, General and Social Psychology Department, Yaroslavl State Pedagogical University, Yaroslavl, Russia, 2005.

[17] R. Abdelra, "Metacognitive awareness and academic motivation and their impact on academic achievement of Ajman University students," Heliyon, vol. 6, pp. 1-8, 2020.

[18] B. Mukha, M. Ashour, and A. Noami, "Examining the motivations and future career aspirations of Qatari pharmacy students and alumni: A case study," Currents in Pharmacy Teaching and Learning, vol. 12, pp. 1329-1339, 2020.

[19] I. Trostinskaia, A. Safonova, and N. Pokrovskaia, "Professionalization of education within the digital economy and communicative competencies," IEEE VI Forum Strategic Partnership of Universities and Enterprises of Hi-Tech Branches (Science. Education. Innovations) (SPUE), pp. 29 -32, 2017.

[20] N. Duta, G. PanisoaraIon, and O. Panisoara, "The effective communication in teaching diagnostic study regarding the academic learning motivation to students," Procedia - Social and Behavioral Sciences, vol. 186, pp. 1007-1012, 2015.

[21] R. Sternberg, H. Roediger, and D. Halpern, Critical Thinking in Psychology, Cambridge University Press, 2007.

[22] T. Scull, C. Malik, A. Morrison, and E. Keefe, "Study protocol for a randomized controlled trial to evaluate a web-based comprehensive sexual health and media literacy education program for high school students," Trials, vol. 21, p. 50, 2020.

Copyright $($ C 2022 by the authors. This is an open access article distributed under the Creative Commons Attribution License which permits unrestricted use, distribution, and reproduction in any medium, provided the original work is properly cited (CC BY 4.0).

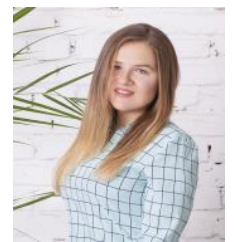

Ponomarenko Tetiana was born on August 24, 1994 in Ukraine. She received a bachelor's degree in psychology in 2016 and a master's degree in psychology in 2018. From 2018, she is a postgraduate student of the Department of Political Psychology and International Relations, Faculty of Psychology National Pedagogical Dragomanov University (NPDU) Kyiv, Ukraine. The topic of her research is "Psychological factors of development of communicative competence of future psychologists in the media space".

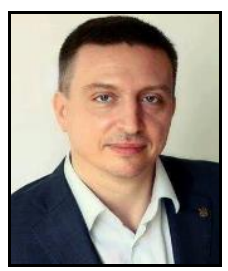

Zelenin Vsevolod was born on September 12, 1969 in Ukraine. PhD, Professor of the Department of Political Psychology and International Relations, Faculty of Psychology National Pedagogical Dragomanov University (NPDU) Kyiv, Ukraine. He is also the head of program for postgraduate programs in the Faculty of Psychology NPDU. Member of the Association of Political Psychologists of Ukraine.

His areas of expertise are political psychology, media psychology, management psychology, and organizational psychology. 